\title{
EPR spectroscopy and its use in planta-a promising technique to disentangle the origin of specific ROS
}

\author{
Anja Steffen-Heins ${ }^{1}$ and Bianka Steffens ${ }^{2 *}$ \\ ${ }^{1}$ Micro- and Nanostructures in Foods, Kiel University, Kiel, Germany \\ 2 Plant Physiology, Philipps-Universität Marburg, Marburg, Germany
}

\section{Edited by:}

Naser A. Anjum, University of

Aveiro, Portugal

Reviewed by:

Naser A. Anjum, University of

Aveiro, Portugal

Preeyaporn Koedrith, Mahidol

University, Thailand

Goran G. Bačić, University of

Belgrade, Serbia

*Correspondence:

Bianka Steffens, Plant Physiology,

Philipps-Universität Marburg,

Karl-von-Frisch-Strasse 8, 35043

Marburg, Germany

e-mail: bianka.steffens@

biologie.uni-marburg.de
While it is widely accepted that reactive oxygen species (ROS) are common players in developmental processes and a large number of adaptations to abiotic and biotic stresses in plants, we still do not know a lot about ROS level control at cellular or organelle level. One major problem that makes ROS hard to quantify and even to identify is their short lifetime. A promising technique that helps to understand ROS level control in planta is the electron paramagnetic resonance (EPR) spectroscopy. Application of the spin trapping method and the spin probe technique by this advanced method enables the quantification and identification of specific ROS in different plant tissues, cells or organelles or under different conditions. This mini review summarizes the knowledge using EPR spectroscopy as a method for ROS detection in plants under different stress conditions or during development. This technique allows disentangling the origin of specific ROS and transient alteration in ROS levels that occur by changes in ROS production and scavenging.

Keywords: electron paramagnetic resonance (EPR) spectroscopy, reactive oxygen species (ROS), ROS detection, spin probe, spin trap

\section{INTRODUCTION}

Reactive oxygen species (ROS) are derivatives of molecular oxygen. The term "ROS" combines non-radical forms of oxygen such as hydrogen peroxide $\left(\mathrm{H}_{2} \mathrm{O}_{2}\right)$, singlet oxygen $\left({ }^{1} \mathrm{O}_{2}\right)$ or ozone $\left(\mathrm{O}_{3}\right)$, and oxygen-centred radicals such as superoxide anion radicals $\left(\mathrm{O}_{2}^{--}\right)$and hydroxyl radicals $(\cdot \mathrm{OH})$. All these kinds of ROS are generated in plants during development or different stresses. The primary ROS is often $\mathrm{O}_{2}^{--}$that is produced either by plasma membrane-located NADPH oxidase or in electron transfer chains of mitochondria (Torres et al., 1998; Blokhina and Fagerstedt, 2010; Shapiguzov et al., 2012). ROS such as $\mathrm{H}_{2} \mathrm{O}_{2}$ are converted in enzymatic or non-enzymatic steps. All ROS are highly active in terms of oxidative modification of lipids, proteins, DNA and RNA. Also, ROS are indispensable in cellular signaling processes.

ROS are involved in the regulation of many internal plant processes such as growth (e.g., Schopfer et al., 2002) and death of specific cells (e.g., Steffens and Sauter, 2009; Steffens et al., 2011, 2012), to name only two. It is therefore indispensable to find out about ROS levels as well as specific ROS in organs, tissues or even cells, and organelles. ROS are however highly reactive and exhibit very short lifetimes that vary from nanoseconds to seconds. ${ }^{\circ} \mathrm{OH}$, for example, reacts with most organic compounds by electron addition or electron transfer (Renew et al., 2005) and has a lifetime of about $10 \mathrm{~ns}$. $\mathrm{O}_{2}^{--}$exhibits a low steady state concentration of around $10^{-10} \mathrm{M}$ in different cell or organelle types (Gardner, 2002). The half-life of $\mathrm{O}_{2}^{--}$depends on its concentration. At a concentration of $10 \mu \mathrm{M} \mathrm{O}_{2}^{*-}$ exhibits a half-life time of $0.2 \mathrm{~ms}$ in water, whereas at a lower concentration of $1 \mu \mathrm{M}$ half-life rises to $20 \mathrm{~ms} .{ }^{1} \mathrm{O}_{2}$ exhibits a lifetime of $2.7 \mu \mathrm{s}$ (Karonen et al., 2014). Effort has been made to develop in planta ROS detection methods that are suitable to identify specific ROS and to quantify them in order to understand ROS signaling and ROS level control. These spectrophotometrical techniques, histochemical or live cell imaging approaches have unfortunately tremendous disadvantages; chlorophyll has to be removed from the tissue for histochemical ROS detection. Quantification of ROS is neither possible with histochemical methods nor with the use of small-molecule fluorescent probes (for review see Steffens et al., 2013). Fluorescent probes, however, benefit from their ability to detect ROS in living cells by confocal laser scanning microscopy.

Electron paramagnetic resonance (EPR; also termed electron spin resonance, ESR) spectroscopy is a widely used method for detecting the presence of unpaired electrons, such as ROS. Using the X-band, EPR is the most specific and even sensitive technique to identify, quantify and visualize the short-lived ROS (Bačić et al., 2008). Nevertheless, it is very challenging to monitor ROS successfully in biological systems due to their very low concentration, the enzymatic defense systems and the different compartments of the living cell. A way to make short-lived ROS detectable by EPR is the application of spin traps or spin probes. In this mini review we will focus on these two methods of ROS detection by EPR in planta.

\section{ROS DETECTION IN PLANTA BY THE SPIN TRAPPING METHOD}

Spin traps are stable, diamagnetic compounds that form longerlived radical species with transient, very reactive radicals with low half-lives of only $10^{-9}$ to $10^{-1} \mathrm{~s}$. The paramagnetic spin adducts are stable for minutes or even hours, accumulate in the tissue and reach a sufficient concentration for detection by EPR (Mojovié et al., 2005). The prerequisites for suitable spin traps are defined by their ability either to exclusively trap one radical species or to 
lead to different specific signature EPR spectra. The sensitivity of the trapping technique depends on the local spin trap concentration, the concentration of the transient radical, the reaction kinetic to form adducts and the stability of these adducts (Bačic et al., 2008). Properties of the spin traps, such as lipophilicity are also crucial for an effective detection of radicals. The trapping technique benefits from the fingerprint spectra of the adducts, allowing identification of the trapped radical species and even quantification by double integration of the whole spectra or the low-field signal by using a calibration curve.

Various radical specific spin traps such as Tiron and 4-POBN are available. Tiron was applied for specific $\mathrm{O}_{2}^{--}$detection in microsomal membranes of Dianthus caryophyllus or roots of Triticum spp. (Mayak et al., 1983; Vylegzhanina et al., 2001; Taiwo, 2008; Table 1). 4-POBN solved in ethanol exclusively detects ${ }^{\circ} \mathrm{OH}$ (Renew et al., 2005; Table 1) by forming a 4-POBN/hydroxyethyl radical adduct generated from oxidation of ethanol by ${ }^{\bullet} \mathrm{OH}$. This spin adduct is stable for hours. Renew et al. (2005) used 4-POBN to perform a region-specific $\cdot \mathrm{OH}$ profiling in roots of Cucumis sativus by detecting individual spin adduct spectra in distinct regions of the root. With this EPR spectroscopy analysis, the growth zone of the root was identified as site of $\bullet \mathrm{OH}$ production (Renew et al., 2005). A couple of studies were done specifically detecting $\cdot \mathrm{OH}$ with 4 -POBN in surrounding medium of growing Zea mays coleoptiles (Schopfer et al., 2002; Liszkay et al., 2003) or in roots of Zea mays and Arabidopsis thaliana (Liszkay et al., 2004; Renew et al., 2005; Table 1). In addition, 4-POBN was applicable to analyze ${ }^{\bullet} \mathrm{OH}$ in single cells of Oryza sativa suspension cultures (Kuchitsu et al., 1995) or even in membranes of Spinacia oleracea and Pisum sativum thylakoids (Borisova et al., 2012). Both spin traps however do not seem to be the best choice in biological systems. The 4-POBN/OH adduct may be converted into a 4-POBN/4-POBN spin adduct during the reaction of peroxidases, whereas Tiron is acidic which decreases intra- and extracellular $\mathrm{pH}$ value and may alter $\mathrm{O}_{2}^{\circ-}$ production (Bačić and Mojovic̀, 2005).

One of the first descriptions of $\mathrm{O}_{2}^{*-}$ detection with the spin trap technique using EPR spectroscopy in planta was given by Habour and Bolton (1975). Harbour and Bolton detected $\mathrm{O}_{2}^{--}$production in chloroplasts of Spinacia oleracea with an $\mathrm{O}_{2}^{*-}$ adduct of DMPO; this spin trap was also used to detect $\mathrm{O}_{2}^{--}$in thylakoid membranes about 20 years later ((Hideg et al., 1994); Table 1). Since then improvement of spin traps with longer lifetime, less degradation of the spin adducts and a faster reaction kinetic, such as the DMPO analogs DEPMPO, EMPO and BMPO, led to a successful trapping of both, $\mathrm{O}_{2}^{*-}$ and $\cdot \mathrm{OH}$ (Figure 1A). DEPMPO is the phosphorylated analog of DMPO. DEPMPO adducts are stable for $22.3 \mathrm{~min}$ and exhibit a lifetime 10 times longer than DMPO adducts. EPR spectroscopy was used to analyze oxygencentered radicals of ${ }^{\circ} \mathrm{OH}$ with DEPMPO in apoplastic fluid of Zea mays roots (Dragišic̀ Maksimovic̀ et al., 2014). During growth, cell wall loosening is facilitated by ${ }^{\circ} \mathrm{OH}$. DEPMPO was effectively used to detect ROS in root cells of Pisum sativum with EPR and to differentiate between $\mathrm{O}_{2}^{--}$and $\cdot \mathrm{OH}$ (Veljovic̀-Jovanovic et al., 2005; Kukavica et al., 2009). Unfortunately, there are four DEPMPO/OOH species, and DEPMPO/OH shows diastereomers (Dikalov et al., 2005), making the identification of radical species more complicated. Both DMPO and DEPMPO lead to the conversion of the $\mathrm{O}_{2}^{*-}$-adduct into the ${ }^{\cdot} \mathrm{OH}$-adduct which underestimates the $\mathrm{O}_{2}^{*-}$ detection (Figure 1A). Transformation of DEPMPO occurs at a slower rate. To avoid the problem of transformation, the carboxylated DMPO analog EMPO and an analog with a large butoxycarbonyl group, BMPO, were developed (Bačić et al., 2008). Both radical specific spin traps are able to exclusively detect $\mathrm{O}_{2}^{--}$(Figure 1A). The EMPO/OOH adduct is eight times more stable than the $\mathrm{DMPO} / \mathrm{OOH}$ adduct. $\mathrm{BMPO} / \mathrm{OOH}$ adducts are slightly more stable than the $\mathrm{EMPO} / \mathrm{OOH}$ adducts because of the large butoxycarbonyl group. Other analogs of the DMPO group, such as DPPMPO, DBPMPO, and DEHPMPO, possess a higher lipophilicity and allow measurements in lipophilic media (Bačić et al., 2008).

Spin traps specific for ${ }^{1} \mathrm{O}_{2}$ are TEMP and TMPD. TEMP was used to specifically detect ${ }^{1} \mathrm{O}_{2}$ in thylakoid membranes of Spinacia oleracea (Fischer et al., 2006), and the more hydrophilic spin trap TMPD was used for ${ }^{1} \mathrm{O}_{2}$ detection in thylakoid and plasma membranes of Spinacia oleracea, Chlamydomonas reinhardtii, or Triticum spp., respectively (Qiu et al., 1995; Fischer et al., 2007; Yadev et al., 2010). ${ }^{1} \mathrm{O}_{2}$ is one important reactive species generated under high light conditions in chloroplasts. It is scavenged by tocopherol and plastochromanol in Arabidopsis thaliana, as was shown by using a tocopherol cyclase-deficient vte1 mutant (Rastogi et al., 2014). The spin trap TMPD was used to analyze the production of ${ }^{1} \mathrm{O}_{2}$ in Arabidopsis thaliana under high light conditions at $1000 \mu \mathrm{mol}$ photons $\mathrm{m}^{-2} \mathrm{~s}^{-1}$ with EPR spectroscopy. In vte 1 mutant plants ${ }^{1} \mathrm{O}_{2}$ production was enhanced under high light, as was shown by using EPR spectroscopy (Rastogi et al., 2014). Combining mutant analysis and ROS detection by EPR spectroscopy will help to understand ROS effects and ROS signaling in planta.

Although spin traps benefit from their ROS specificity, with some of them detecting exclusively one ROS intermediate, high spin trap concentrations between 10 and $100 \mathrm{mM}$ have to be used to reach an adequate sensitivity (Dikalov et al., 2011). Potential toxic effects, for example inhibition of photosynthesis, might occur at concentrations of more than $25 \mathrm{mM}$. Spin traps are often solved in ethanol; hence they are unsuited for the use in planta or other biological systems. Adducts may be transformed into other products (Figure 1A) or they may be reduced by plant metabolites into molecules without EPR activity.

\section{SPIN PROBE TECHNIQUE-A BETTER CHOICE FOR ROS DETECTION IN PLANTA?}

To circumvent the drawbacks of spin trapping technique the use of spin probes for ROS detection by EPR spectroscopy is favored. There are two possibilities of the use of spin probes. Commonly used spin probes are, on the one hand, endogenous nitroxides that are reduced by ROS to EPR-silent hydroxylamines. On the other hand, endogenous cyclic hydroxylamines (CHAs) are oxidized by ROS to EPR-active nitroxides (Figure 1B). Nitroxide radicals are stable products of CHAs that are much more stable than other known spin adducts. The three types of rings commonly used for nitroxide spin-probes are piperidine, pyrrolidine (e.g., DCP-H; Table 1) and doxyl (doxyl stearates). Nitroxides offer different properties and are more or less stable and reactive. In addition, 
Table 1 | EPR technique used for detection of ${ }^{\bullet} \mathrm{OH}, \mathrm{O}_{2}^{\bullet-}$, and ${ }^{1} \mathrm{O}_{2}$ in planta.

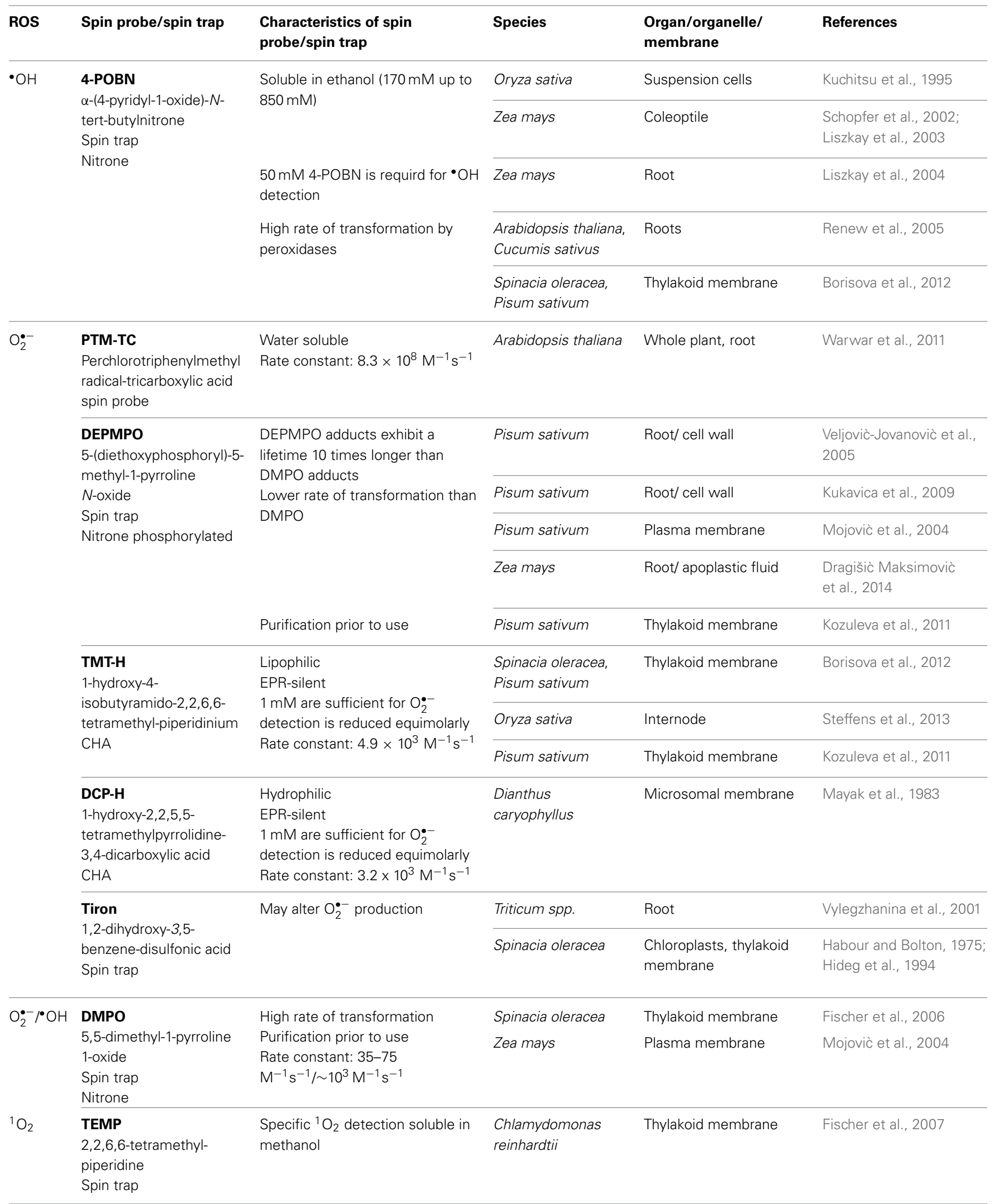


Table 1 | Continued

\begin{tabular}{|c|c|c|c|c|c|}
\hline ROS & Spin probe/spin trap & $\begin{array}{l}\text { Characteristics of spin } \\
\text { probe/spin trap }\end{array}$ & Species & $\begin{array}{l}\text { Organ/organelle/ } \\
\text { membrane }\end{array}$ & References \\
\hline & \multirow{2}{*}{$\begin{array}{l}\text { TEMPD/TMPD } \\
\text { 2,2,6,6-tetramethyl-4- } \\
\text { piperidone } \\
\text { Spin trap }\end{array}$} & \multirow[t]{2}{*}{ Hydrophilic } & Spinacia oleracea & Thylakoid membrane & Yadev et al., 2010 \\
\hline & & & $\begin{array}{l}\text { Arabidopsis thaliana } \\
\text { (wild type, vte1) }\end{array}$ & Chloroplasts & Rastogi et al., 2014 \\
\hline
\end{tabular}

Commonly used spin traps or probes proper to detect ROS in different species, organs, organelles or membrane fractions. If available, rate constants of spin traps or probes toward specific ROS. Characteristics of each spin probe/spin trap summarized. This table gives a broad overview of EPR measurements in planta.

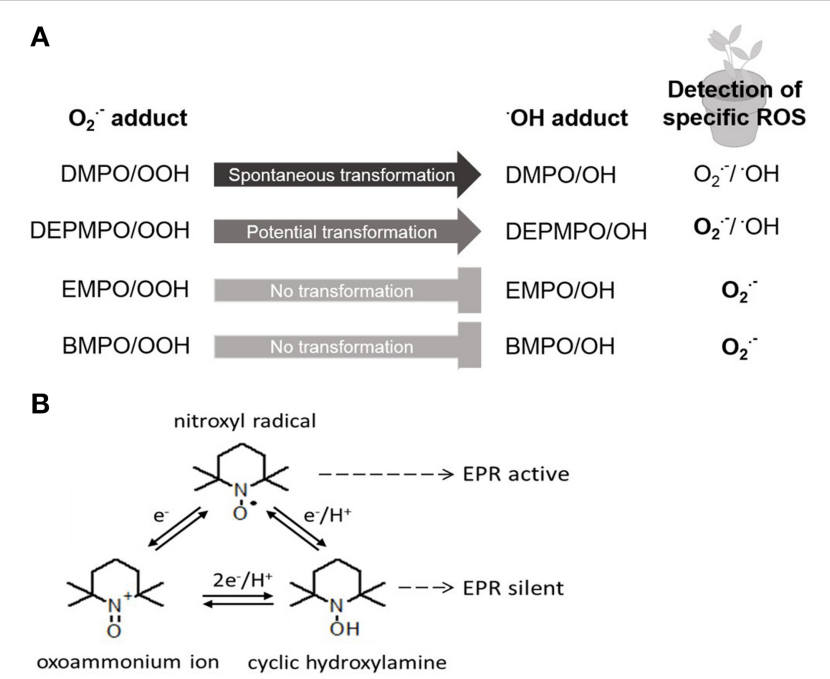

FIGURE 1 | Principles of spin trapping and spin probe method. (A) Spin trap DMPO and its analogs DEPMPO, EMPO, and BMPO are differentially used for detection of specific ROS via EPR in planta. Detailed description in text. (B) Interconversion of nitroxyl radical allows two principles of the spin probe technique using endogenous nitroxides or cyclic hydroxylamines for EPR analysis. Detailed description in text.

nitroxides are hydrophilic or lipophilic, charged or neutral and hence applicable to various EPR spin-probing experiments in redox research (Kocherginsky and Swartz, 1995).

Endogenous nitroxides may be reduced by several enzymatic processes such as ascorbate or glutathione relating to the antioxidative status of the organism and therefore to its oxidative status (Valgimigli et al., 2001). A recent study demonstrates that the nitroxide TEMPO (2,2,6,6-tetramethylpiperidine-N-oxyl) and its derivates react with oxygen-centered radicals under acidic conditions as well (Amorati et al., 2010), being a most effective antioxidant. Spin probes can be reduced by $\cdot \mathrm{OH}$ and $\mathrm{O}_{2}^{\bullet-}$ without processes analogous to $\mathrm{OOH} / \mathrm{OH}$ adduct transformation. They exhibit an intense EPR signal allowing quantitative analysis due to the high signal-to-noise ratio. Localization of free radical generation is possible, since spin probes located in or excluded from the membranes are available.

The spin probe technique does however not provide any information to identify specific radical species. Apart from the redox status and ROS detection spin probes offer, via their EPR spectra, information on their mobility and different characteristics of their environment such as viscosity, $\mathrm{pH}, \mathrm{pO}_{2}$, and temperature (Kocherginsky and Swartz, 1995). Bačić and Mojovic (2005) therefore recommended combining the spin-probe and spin-trap technique to study free radical species produced in biological systems effectively.

CHAs, such as TMT-H and DCP-H, become paramagnetic after oxidation, are EPR-silent and are reduced equimolarly by several ROS into EPR-active nitroxides. The very fast reaction between ROS and hydroxylamine is a major advantage compared with spin traps. For example, the rate constant of the spin trap DMPO to form the $\mathrm{O}_{2}^{\circ-}$-adduct DMPO/OOH is $35-75 \mathrm{M}^{-1} \mathrm{~s}^{-1}$ (Dikalov et al., 2002), whereas the rate constant of the CHA TEMPO-H to form the $\mathrm{O}_{2}^{--}$-adduct is $10^{3}-10^{4} \mathrm{M}^{-1} \mathrm{~s}^{-1}$ (Dikalov et al., 2011). The efficiency of CHAs to detect $\mathrm{O}_{2}^{--}$is therefore very high; hence very low concentrations of CHAs are necessary to detect $\mathrm{O}_{2}^{--}$, and side effects can be minimized. For example, $1 \mathrm{mM}$ CHAs are sufficient for $\mathrm{O}_{2}^{--}$detection whereas concentrations of $10-50 \mathrm{mM}$ of spin traps are needed. One disadvantage is the presence of $\mathrm{Cu}^{2+}$ and $\mathrm{Fe}^{3+}$ in biological systems leading to autoxidation of CHAs. This problem is decreased by the use of metal chelators (Dikalov et al., 1999). Since the reaction of CHAs toward ROS is unspecific, control experiments with supplements of ROS-scavenging enzymes, such as superoxide dismutase or catalase, or other non-enzymatic scavengers have to be performed for the identification of specific ROS (Dikalov et al., 2011).

The lipophilic spin probe TMT-H was applied to analyze whether ethylene influences ROS levels in internodes of Oryza sativa (Steffens et al., 2013). Using the spin-trapping method showed that ethylene enhances ROS levels in the rice internode. ROS were identified as signals that induce parenchymal cell death resulting in aerenchyma formation in specific regions of the rice internodes (Steffens et al., 2011). The paramagnetic, water-soluble spin probe PTM-TC was used to detect $\mathrm{O}_{2}^{--}$via a one-dimensional (1D) imaging method in whole Arabidopsis thaliana plants or roots after injury of the apex (Warwar et al., 2011). Negatively charged PTM-TC does not penetrate membranes, is very specific for $\mathrm{O}_{2}^{--}$detection and grants a distinct single-line EPR spectrum. After reaction of paramagnetic spin probes with ROS the signal is lost, and the loss of signal indicates the presence of ROS. The spin probe method can be used for in planta $\mathrm{O}_{2}^{*-}$ detection with an adequate temporal and spatial resolution. The authors conclude that the wound signal in the Arabidopsis root is transmitted at a rate of around $1-3 \mathrm{~cm} / \mathrm{min}$. 
By these high resolution scans, the authors show that the root tip at around $0.7 \mathrm{~mm}$ possesses more ROS than the part at around $2.2 \mathrm{~mm}$. In addition, during injury ROS levels change within the whole plant. Leaf injury, for example, results in $\mathrm{O}_{2}^{--}$production in roots. This was also shown by the use of the stable spin probe that possesses a relatively sharp and strong signal of around $1 \mathrm{G}$ (Warwar et al., 2011).

\section{DISENTANGLING OF SPECIFIC ROS LEVELS AND ROS SIGNALING VIA EPR SPECTROSCOPY IN PLANTS}

Despite the abovementioned issues, EPR spectroscopy is an excellent method for analyzing levels of ROS and for identifying specific ROS. In complex biological systems such as plant cells, compartmentation impedes the possibility of ROS detection and quantification. Fortunately, spin probes of different polarities and charges resulting in different cell permeability are available. These properties allow site-specific ROS detection with a higher sensitivity than nitrone spin traps. This is mainly due to the high reactivity of radicals. The reaction site of radicals and radical spin probes is very close to their generation or solubilisation site (Heins et al., 2007). The compartments in plant cells, in particularly the membranes, are comparable to simple model systems where the compartments act as barriers for stable radicals. It is therefore crucial for an efficient detection to define the solubilisation site of the spin probe close to the site of radical generation.

Detection of different ROS in membrane fractions, such as thylakoids (e.g., Hideg et al., 1994; Table 1) and plasma membranes (Qiu et al., 1995; Mojovic̀ et al., 2004; for details: Table 1) have been performed over the years using spin traps. A more sophisticated approach was used to analyze production of ROS in the photosynthetic electron transport chain in chloroplasts under high light with CHAs with different lipophilicities (Kozuleva et al., 2011; Borisova et al., 2012). Even in membrane systems, such as thylakoids, ROS production within or without the thylakoid membranes could be distinguished. As the spin probe TMT-H exhibits a high lipophilicity, $\mathrm{O}_{2}^{--}$measurements within thylakoid membranes are possible (Kozuleva et al., 2011; Borisova et al., 2012), while the hydrophilic spin probe DCP-H allows measurement of $\mathrm{O}_{2}^{*-}$ outside the membranes (Kozuleva et al., 2011). At $\mathrm{pH} 7, \mathrm{DCP}-\mathrm{H}$ is negatively charged and hence excluded from membranes. These CHAs are excellent tools for ROS detection with high spatial resolution.

To visualize the distribution of free radicals in tissues or cell compartments with a high spectral resolution, $1 \mathrm{D}$ - to $3 \mathrm{D}-\mathrm{X}-$ band EPR imaging (EPRI) experiments are an excellent choice. The application of spin traps for EPRI experiments in planta is limited due to solvent compatibility with living tissue, high concentrations of spin traps needed and a multiple signal spectrum (Warwar et al., 2011). The use of stable exogenous spin probes that possess a relatively sharp and strong signal of around $1 \mathrm{G}$ enable the acquisition of EPRI images (Yan et al., 2008). In particular, the application of ${ }^{15} \mathrm{~N}$ spin probes with a lower linewidth and a lower detection limit enhances spatial resolution (Yan et al., 2008). There are few successful 2D- or 3D-spectral-spatial EPRI applications found for herbal foodstuff such as seeds of Sesamum indicum (Nakagawa and Hara, 2015), Piper nigrum (Nakagawa and Epel, 2014) and Helianthus annus (Levêque et al., 2008) and coffee beans (Levêque et al., 2008); however, there are not many examples for in planta ROS imaging. Possibly, the different strategies that will be followed to reduce biological responsibility of spin probes in living tissues focusing on narrow EPR lines, tissue-targeting specificity and high stability (Yan et al., 2008) will improve the possibilities for EPRI application in planta. The visualization of spatiotemporal intracellular ROS dynamics by time-laps imaging in intact plants, organs, organelles, or even different membrane systems by EPRI would provide new insights into the ROS production, their scavenging and possibly into the ROS signaling during plant development and different stresses occurring in a plants' life.

\section{REFERENCES}

Amorati, R., Pedulli, G. F., Pratt, D. A., and Valgimigli, L. (2010). TEMPO reacts with oxygen-centered radicals under acidic conditions. Chem. Commun. 46, 5139-5141. doi: 10.1039/c0cc00547a

Bačić, G., and Mojovic̀, M. (2005). EPR spin trapping of oxygen radicals in plants. A methodological overview. Ann. N.Y. Acad. Sci. 1048, 230-243. doi: 10.1196/annals.1342.021

Bačić, G., Spasojević, I., Šećerov, B., and Mojović, M. (2008). Spin-trapping of oxygen free radicals in chemical and biological systems: new traps, radicals and possibilities. Spectrochim. Acta A Mol. Biomol. Spectrosc. 69, 1354-1366. doi: 10.1016/j.saa.2007.09.047

Blokhina, O. B., and Fagerstedt, K. V. (2010). Reactive oxygen species and nitric oxide in plant mitochondria: origin and redundant regulatory systems. Physiol. Plant. 138, 447-462. doi: 10.1111/j.1399-3054.2009.01340.x

Borisova, M. M., Kozuleva, M. A., Rudenko, N. N., Naydov, I. A., Klenina, I. B., and Ivanov, B. N. (2012). Photosynthetic electron flow to oxygen and diffusion of hydrogen peroxide through the chloroplast envelope via aquaporins. Biochim. Biophys. Acta 1817, 1314-1321. doi: 10.1016/j.bbabio.2012.02.036

Dikalov, S. I., Dikalova, A. E., and Mason, R. P. (2002). Noninvasive diagnostic tool for inflammation-induced oxidative stress using electron spin resonance spectroscopy and an extracellular cyclic hydroxylamine. Arch. Biochemi. Biophys. 402, 218-226. doi: 10.1016/S0003-9861(02)00064-4

Dikalov, S. I., Fink, B., Skatchkov, M., and Bassenge, E. (1999). Comparison of glyceryl trinitrate-induced with pentaerythrityl tetranitrate-induced in vivo formation of superoxide radicals: effect of vitamin C. Free Radic. Biol. Med. 27, 170-176. doi: 10.1016/S0891-5849(99)00066-0

Dikalov, S. I., Jiang, J. J., and Mason, R. P. (2005). Characterization of the high-resolution ESR spectra of superoxide radical adducts of 5(diethoxyphosphoryl)-5-methyl-1-pyrroline N-oxide (DEPMPO) and 5,5dimethyl-1-pyrroline N-oxide (DMPO). Analysis of conformational exchange. Free Radic. Res. 39, 825-836. doi: 10.1080/10715760500155688

Dikalov, S. I., Kirilyuk, I. A., Voinov, M., and Grigor'ev, I. A. (2011). EPR detection of cellular and mitochondrial superoxide using cyclic hydroxylamines. Free Radic. Res. 45, 417-430. doi: 10.3109/10715762.2010.540242

Dragišic̀ Maksimovic̀, J. J., Živanovic̀, B. D., Maksimovic̀, V. M., Mojovic̀, M. D., Nikolic, M. T., and Vučinić, Ž. B. (2014). Filter strip as a method of choice for apoplastic fluid extraction from maize roots. Plant Sci. 223, 49-58. doi: 10.1016/j.plantsci.2014.03.009

Fischer, B. B., Eggen, R. I., Trebst, A., and Krieger-Liszkay, A. (2006). The glutathione peroxidase homologous gene Gpxh in Chlamydomonas reinhardtii is upregulated by singlet oxygen produced in photosystem II. Planta 223, 583-590. doi: 10.1007/s00425-005-0108-9

Fischer, B. B., Krieger-Liszkay, A., Hideg, E., Snyrychová, I., Wiesendanger, M., and Eggen, R. I. (2007). Role of singlet oxygen in chloroplast to nucleus retrograde signaling in Chlamydomonas reinhardtii. FEBS Lett. 581, 5555-5560. doi: 10.1016/j.febslet.2007.11.003

Gardner, P. R. (2002). Aconitase: sensitive target and measure of superoxide. Methods Enzymol. 349, 9-23. doi: 10.1016/S0076-6879(02)49317-2

Habour, J. R., and Bolton, J. R. (1975). Superoxide formation in spinach chloroplasts: electron spin resonance detection by spin trapping. Biochem. Biophys. Res. Commun. 64, 803-807. doi: 10.1016/0006-291X(75) 90118-7 
Heins, A., McPhail, D. B., Sokolowski, T., Stöckmann, H., and Schwarz, K. (2007). The location of phenolic antioxidants and radicals at interfaces determines their activity. Lipids 42, 573-582. doi: 10.1007/s11745-007-3052-6

Hideg, E., Spetea, C., and Vass, I. (1994). Singlet oxygen and free radical production during acceptor- and donor-side-induced photoinhibition: studies with spin trapping EPR spectroscopy. Biochim. Biophys. Acta Bioenerg. 1186, 143-152. doi: 10.1016/0005-2728(94)90173-2

Karonen, M., Mattila, H., Huang, P., Mamedov, F., Styring, S., and Tyystjärvi, E. (2014). A tandem mass spectrometric method for singlet oxygen measurement. Photochem. Photobiol. 90, 965-971. doi: 10.1111/php.12291

Kocherginsky, N., and Swartz, H. M. (1995). Nitroxide Spin Labels. Reactions in Biology and Chemistry. New York, NY: CRC Press.

Kozuleva, M., Klenina, I., Proskuryakov, I., Kirilyuk, I., and Ivanov, B. (2011). Production of superoxide in chloroplast thylakoid membranes - ESR study with cyclic hydroxylamines of different lipophilicity. FEBS Lett. 585, 1067-1071. doi: 10.1016/j.febslet.2011.03.004

Kuchitsu, K., Kosaka, H., Shiga, T., and Shibuya, N. (1995). EPR evidence for generation of hydroxyl radical triggered by $N$-acetylchitooligosaccharide elicitor and a protein phosphatase inhibitor in suspension-cultured rice cells. Protoplasma 188, 138-142. doi: 10.1007/BF01276805

Kukavica, B., Mojovic̀, M., Vuèinic̀, Z., Maksimovic̀, V., Takahama, U., and Veljovic̀ Jovanovic̀, S. (2009). Generation of hydroxyl radical in isolated pea root cell wall, and the role of cell wall-bound peroxidase, Mn-SOD and phenolics in their production. Plant Cell Physiol. 50, 304-317. doi: 10.1093/pcp/pcn 199

Levêque, P., Godechal, Q., and Gallez, B. (2008). EPR spectroscopy and imaging of free radicals in food. Isr. J. Chem. 48, 19-26. doi: 10.1560/IJC.48.1.19

Liszkay, A., Kenk, B., and Schopfer, P. (2003). Evidence for the involvement of cell wall peroxidase in the generation of hydroxyl radicals mediating extension growth. Planta 217, 658-667. doi: 10.1007/s00425-003-1028-1

Liszkay, A., van der Zalm, E., and Schopfer, P. (2004). Production of reactive oxygen intermediates $\left(\mathrm{O}_{2}^{--}, \mathrm{H}_{2} \mathrm{O}_{2}\right.$, and $\left.\mathrm{OH}\right)$ by maize roots and their role in wall loosening and elongation growth. Plant Physiol. 136, 3114-3123. doi: 10.1104/pp.104.044784

Mayak, S., Legge, R. L., and Thompson, J. E. (1983). Superoxide radical production by microsomal membranes from senescing carnation flowers: an effect on membrane fluidity. Phytochemistry 22, 1375-1380.

Mojovié, M., Spasojevic̀, I., Vultetic̀, M., Vuèinic̀, Z., and Baèic̀, G. (2005). An EPR spin-probe and spin-trap study of the free radicals produced by plant plasma membranes. J. Serb. Chem. Soc. 70, 177-186. doi: 10.2298/JSC0502177M

Mojovic̀, M., Vuletic̀, M., Bacic̀, G. G., and Vucinic̀, Z. (2004). Oxygen radicals produced by plant plasma membranes: an EPR spin-trap study. J. Exp. Bot. 55, 2523-2531. doi:10.1093/jxb/erh266

Nakagawa, K., and Epel, B. (2014). Locations of radical species in black pepper seeds investigated by CW EPR and $9 \mathrm{GHz}$ EPR imaging. Spectrochim. Acta A Mol. Biomol. Spectrosc. 131, 342-346. doi: 10.1016/j.saa.2014.04.100

Nakagawa, K., and Hara, H. (2015). Investigation of radical locations in various sesame seeds by CW EPR and 9-GHz EPR imaging. Free Radic. Res. 49, 1-6. doi: $10.3109 / 10715762.2014 .967691$

Qiu, Q.-S., Cheng, P., and Liang, H.-G. (1995). Characterization of the NAD(P)H oxidation by purified plasma membrane vesicles using a spin-trapping EPR method. J. Plant Physiol. 146, 445-449.

Rastogi, A., Yadav, D. K., Szymañska, R., Kruk, J., Sedláøová, M., and Pospíšil, P. (2014). Singlet oxygen scavenging activity of tocopherol and plastochromanol in Arabidopsis thaliana: relevance to photooxidative stress. Plant Cell Environ. 37, 392-401. doi: 10.1111/pce.12161

Renew, S., Heyno, E., Schopfer, P., and Liszkay, A. (2005). Sensitive detection and localization of hydroxyl radical production in cucumber roots and Arabidopsis seedlings by spin trapping electron paramagnetic resonance spectroscopy. Plant J. 44, 342-347. doi: 10.1111/j.1365-313X.2005.02528.x

Schopfer, P., Liszkay, A., Bechtold, M., Frahry, G., and Wagner, A. (2002). Evidence that hydroxyl radicals mediate auxin-induced extension growth. Planta 214, 821-828. doi: 10.1007/s00425-001-0699-8
Shapiguzov, A., Vainonen, J. P., Wrzaczek, M., and Kangasjärvi, J. (2012). ROStalk - how the apoplast, the chloroplast, and the nucleus get the message through. Front. Plant Sci. 3:292. doi: 10.3389/fpls.2012.00292

Steffens, B., Geske, T., and Sauter, M. (2011). Aerenchyma formation in the rice stem and its promotion by $\mathrm{H}_{2} \mathrm{O}_{2}$. New Phytol. 190, 369-378. doi: 10.1111/j.1469-8137.2010.03496.x

Steffens, B., Kovalev, A., Gorb, S. N., and Sauter, M. (2012). Emerging roots alter epidermal cell fate through mechanical and reactive oxygen species signaling. Plant Cell 24, 3296-3306. doi: 10.1105/tpc.112.101790

Steffens, B., and Sauter, M. (2009). Epidermal cell death in rice is confined to cells with a distinct molecular identity and is mediated by ethylene and $\mathrm{H}_{2} \mathrm{O}_{2}$ through an autoamplified signal pathway. Plant Cell 21, 184-196. doi: 10.1105/tpc.108.061887

Steffens, B., Steffen-Heins, A., and Sauter, M. (2013). Reactive oxygen species mediate growth and death in submerged plants. Front. Plant Sci. 4:179. doi: $10.3389 /$ fpls.2013.00179

Taiwo, F. A. (2008). Mechanism of tiron as scavenger of superoxide ions and free electrons. Spectroscopy 22, 491-498. doi: 10.3233/SPE-2008-0362

Torres, M. A., Onouchi, H., Hamada, S., Machida, C., Hammond-Kosack, K. E., and Jones, J. D. (1998). Six Arabidopsis thaliana homologues of the human respiratory burst oxidase (gp91phox). Plant J. 14, 365-370.

Valgimigli, L., Pedulli, G. F., and Paolini, M. (2001). Measurement of oxidative stress by EPR radical-probe technique. Free Radic. Biol. Med. 31, 708-716. doi: 10.1016/S0891-5849(01)00490-7

Veljović-Jovanović, S., Kukavica, B., Cvetic̀, T., Mojovič, M., and Vucinič, Z. (2005). Ascorbic acid and the oxidative processes in pea root cell wall isolates: characterization by fluorescence and EPR spectroscopy. Ascorbic acid and the oxidative processes in pea root cell wall isolates: characterization by fluorescence and EPR spectroscopy. Ann. N.Y. Acad. Sci. 1048, 500-504. doi: 10.1196/annals.1342.076

Vylegzhanina, N. N., Gordon, L. K., Minibayeva, F. V., and Kolesnikov, O. P. (2001) Superoxide production as a stress response of wounded root cells: ESR spintrap and acceptor methods. Appl. Magn. Reson. 21, 63-70. doi: 10.1007/BF031 62440

Warwar, N., Mor, A., Fluhr, R., Pandian, R. P., Kuppusamy, P., and Blank, A. (2011). Detection and imaging of superoxide in roots by an electron spin resonance spin-probe method. Biophys. J. 101, 1529-1538. doi: 10.1016/j.bpj.2011. 07.029

Yadev, D. K., Kruk, J., Sinha, R. K., and Pospíšil, P. (2010). Singlet oxygen scavenging activity of plastoquinol in photosystem II of higher plants: electron paramagnetic resonance spin-trapping study. Biochim. Biophys. Acta 1797, 1807-1811. doi: 10.1016/j.bbabio.2010.07.003

Yan, G., Peng, L., Jian, S., Li, L., and Bottle, S. E. (2008). Spin probes for electron paramagnetic resonance imaging. Chin. Sci. Bull. 53, 3777-3789. doi: 10.1007/s11434-008-0520-1

Conflict of Interest Statement: The authors declare that the research was conducted in the absence of any commercial or financial relationships that could be construed as a potential conflict of interest.

Received: 29 November 2014; accepted: 16 February 2015; published online: 03 March 2015.

Citation: Steffen-Heins A and Steffens B (2015) EPR spectroscopy and its use in planta-a promising technique to disentangle the origin of specific ROS. Front. Environ. Sci. 3:15. doi: 10.3389/fenvs.2015.00015

This article was submitted to Environmental Toxicology, a section of the journal Frontiers in Environmental Science.

Copyright (c) 2015 Steffen-Heins and Steffens. This is an open-access article distributed under the terms of the Creative Commons Attribution License (CC BY). The use, distribution or reproduction in other forums is permitted, provided the original author(s) or licensor are credited and that the original publication in this journal is cited, in accordance with accepted academic practice. No use, distribution or reproduction is permitted which does not comply with these terms. 